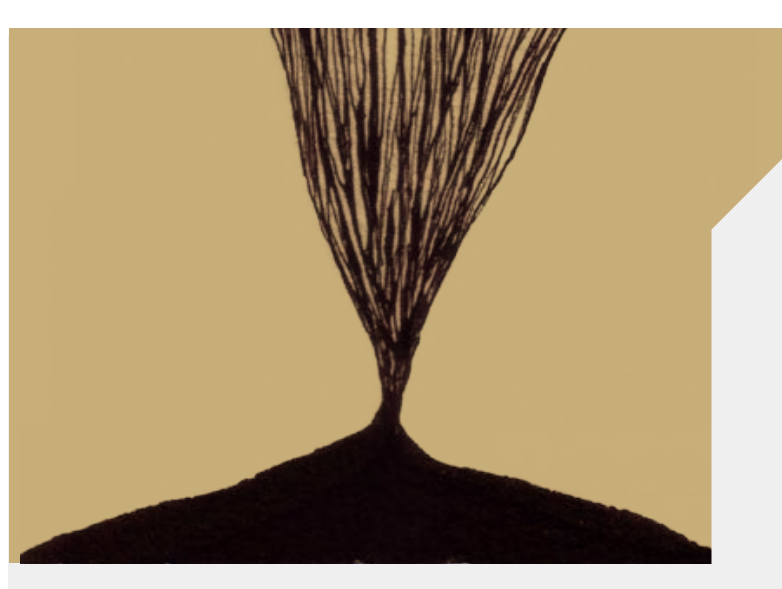

\section{UMA ATRIZ E UM CORAÇÃO ENTRE SHAKESPEARE E BECKETT}

\section{RESENHA DO ESPETÁCULO TEATRAL DISCURSO DO CORAÇÃO INFARTADO, UM SOLO DE SILVANA STEIN, DIREÇÃO E DRAMATURGIA DE RICARDO ALVES JR E SILVANA STEIN*}

Henrique Brener Vertchenko* Mestrando pelo Programa de Pós-Graduação em História da UFMG.

"Dentro do peito eu tinha algo lutando Que me impedia de dormir. [...]"1

SHAKESPEARE, William. Hamlet In: BLOOM, Harold. Hamlet: poema ilimitado. Tradução de José Roberto O`Shea. Inclui texto integral de "Hamlet", traduzido por Anna Amélia de Queiroz Carneiro de Mendonça. Rio de Janeiro: Objetiva, 2004. pp. 301.
Quando adentramos, o espaço é estabelecido por um grande retângulo preto no chão, uma cadeira branca, uma geladeira branca deitada e os contornos de uma porta. Uma figura, vestindo paletó preto, como se vinda de um plano profundo, se aproxima e penetra o espaço retangular. A luz se torna fria. Trata-se de um velho ator cômico, Horácio - interpretado irrepreensivalmente pela atriz Silvana Stein -, e de seu apartamento. Ele demonstra números cômicos, patéticos e fracassados, os quais interpretou a vida inteira e confessa que, em essência, sempre sonhou ser um grande espetáculo fez sua temporada de estréla de 05 de março a 17 de abril de 2013 na Funarte/MG, em Belo Horizonte. ator dramático, "encenando Hamlet, de Shakespeare, pelos palcos da vida”. O que vemos é uma noite de insônia do personagem. Ele é atormentado pelos sons provenientes da vizinha no apartamento do andar de cima e por seus consecutivos infartos, caracterizados por uma sensação dolorosa contagiante, pela luz quente nas paredes marcando momentos primororsos em provocar o desespero pela iminência da morte. Já para as interferências da vizinha, são criados "bolsões" de espaços sonoros onde se mesclam espaços da ordem da realidade - como passos, porta, chuveiro, copo quebrando - e da ordem da "fantasia", corporificada pela incessante troca de canais da televisão, que culmina no 
filme "Hamlet", clássico de 1948 dirigido e interpretado por Laurence Olivier. Não por acaso, em uma das trocas de canal podemos ouvir de uma TV portuguesa que "no ano passado morreram 1220 idosos, e morreram sozinhos", alusão à condição do próprio Horácio. Dessa maneira, a narrativa sonora é fundamental, já que impulsiona as ações do velho e até mesmo os seus infartos, todos vivenciados no corpo pela atriz. O desenho sonoro é dramatúrgico. Ao ouvirmos os primeiros acordes do filme "Hamlet", percebe-se no personagem uma transformação, uma passagem mergulhada em um êxtase agonizante e apaixonado, em que desmancha sua maquiagem ligada ao passado cômico e faz a difícil escolha pela plenitude, pela vontade do ser e de ser. A partir de então, o espetáculo se desenvolve como um jogo entre a realidade solitária do personagem e seus devaneios em relação à tragédia mais conhecida de William Shakespeare, que passam pelas figuras de Ofélia, Gertrudes, pelo rei Hamlet, pelo príncipe Hamlet.

Esses caprichos da imaginação de Horácio só podem se estabelecer sobre o nada, o vazio, a espera que configura a sua existência. Para se reconhecer no mundo, ele se relaciona com as interferências de outros espaços que cruzam esse seu vazio, como a vizinha, uma ligação de seu filho, seu cachorro Hamlet, e, assim, cria um espaço imaginativo próprio. Há, também, uma eleição de objetos representativos dos personagens shakesperianos que impulsionam nosso imaginário - como a coroa do fantasma do pai, a caveira, um galho para Ofélia - criando uma possível rede de mobilizações do imaginário. Dessa maneira, o espaço sonoro mobiliza Horácio, que age e nos mobiliza, ativando toda uma cadeia de imaginário acerca da história quase mitológica do príncipe da Dinamarca. Além disso, os demais elementos cênicos geram um vazio da existência espacializado, em escolhas minimalistas. $\mathrm{O}$ cachorro nunca atende aos chamados $\mathrm{e}$ a ração despejada em sua vasilha não existe materialmente, a geladeira não conserva comida e sim objetos da memória e do desejo.

Em determinado momento, Horácio recebe uma chamada do filho William em seu celular (talvez, o toque do telefone em forma de "funk" seja o único momento de estranheza a quebrar a coesão do espetáculo). Ele conta-lhe notícias que possam disfarçar a sua solidão, como na passagem em que diz estar acontecendo uma festa em seu apartamento e simula abrir latas e conversar com pessoas. Também declama o famoso monólogo de Hamlet, "ser ou não ser", ao telefone, seguida da bem-humorada frase "não é bolinho!", para exprimir a densidade do texto. No entanto, ao final da declamação, seu coraç̃o sofre mais um infarto e o velho diz: "William, eu preciso desligar. A festa tá pegando fogo aqui!". É a disritmia, a festa em seu coração doente que não cessa, seja pela doença 
ou pelo arrebatamento causado pela obra shakesperiana. A forma com que Horácio sai da crise de seu coração é de uma solidão profunda, caminhando até a cadeira, se assentando e chamando pelo cão Hamlet. Ele chama com a melancolia de quem, discretamente, clama por companhia, depois se senta, cobre o rosto com um lenço dizendo "morrer, dormir". Nesse pequeno trecho, a evocação de duas palavras do monólogo de Hamlet ganha novos contornos possíveis de intensa carga poética, seja pela ação de Silvana ao cobir o rosto com o lenço, seja pelo fato de Horácio não conseguir dormi devido à insônia, e, ainda, ser inexorável a sua espera pela morte. "Morrer, dormir": na insônia e na solidão, essas são as suas duas possibilidades.No entanto, ele acaba sonhando pelo impedimento de dormir causado pela vizinha, e realiza o trecho seguinte do monólogo de Hamlet,em que é dito "Morrer, dormir. Talvez sonhar.". Nesse "sonhar", silenciado por baixo do lenço, é que Horácio preenche o seu tempo para se manter e se sentir vivo.

Por fim, após a vizinha trocar várias vezes de canal ela volta para o filme "Hamlet" e o velho reconhece euforicamente o trecho "to be or not to be". Ele pega, então, uma caveira cravejada de espelhos na geladeira para encenar junto ao som do filme seu trecho favorito. É quando tem um derradeiro infarto, com a caveira junto ao peito, após Laurence Olivier dizer "to be or not to be, that is the question". As luzes se apagam. Percebe-se, então, que o espetáculo cria um território de linguagem próprio,em que a articulação dos elementos cênicos é de tal forma praticamente invisível a ponto de formarem uma única obra, coesa e homogênea. O texto, com toda ampliação que o termo acarreta hoje, é desenhado no espaço e o atravessa. Assim, o contemporâneo da obra não se dá pela hoje usual fragmentação, pela estruturação em "quebra-cabeça", mas sim pelo fazer-se revelar de uma obra coesa, unitária, cuja própria existência dá a ver a desorientação e a falência do projeto de homem moderno, encarcerado em sua solidão, carente de um sentido para sua existência. Por outro lado, a leveza dos recursos interpretativos de Silvana ameniza a amargura existencial do velho e oferece ao público um terreno bem humorado para fruição. A pesquisa da atriz em torno de personagens masculinos, as referências às linguagens clownesca, bufonesca e do cinema mudo, aliadas a um carismático contato direto com o público, revelam uma rara artista imbuída de potencial técnico preciso e domínio reflexivo sobre sua obra. Ao mesmo tempo, a direção, compartilhada pela própria Silvana Stein e por Ricardo Alves Jr., é certeira ao criar o universo angustiante em que está mergulhado Horácio.

Uma análise cuidadosa permite ver que "Discurso do coração infartado" é espetáculo ponto de interseção, diálogo e embate entre a obra de dois dos maiores canônes da literatura 
2. BLOOM, Harold. Shakespeare: a invenção do humano. Tradução de José Roberto O Shea. Rio de Janeiro: Objetiva, 2001. dramática ocidental, separados por quase 400 anos: William Shakespeare e Samuel Beckett. A partirdo pensamento de Harold Bloom, ${ }^{2}$ o bardo inglês reinventou o que hoje entendemos por humano ao criar personagens extremamente complexos que se desenvolvem por meio de reflexões e estímulos interiores. Essa capacidade de se "auto-recriar" a partir de vozes interiores teria levado a um "caminho de individuação" fundamental como paradigma para a cultura moderna ocidental centrada na ideia de sujeito e na de sua autoconsciência. Não seria necessário que o espetáculo colocasse mais textos de "Hamlet", nem mais referências à sua história, tendo em vista o alcance dessa obra na cultura ocidental e a força do personagem no imaginário intelectual e artístico modernos. Tal qual Hamlet, Horácio tem um coração que "bate com pontadas e flechadas do destino feroz", mas para um sentido que vai além do metafísico e encontra sua radicalidade em uma impossibilidade física: o infarto Ele tem a autoconsciência de que não tem muito tempo de vida e, parafraseando o possível título de Bloom para o texto de Shakespeare ("Sacio com palavras meu coração"), sacia com palavras (mas não somente) seu coração. Sua existência desfila características de diversos personagens da tragédia. Assim, ele é como Ofélia, que em delírio flutua e canta velhas canções antes de "sufocar no lodo". Mas é também como Horácio, o amigo de Hamlet, ao qual seu nome faz referência direta. Horácio é constante plátéia e interlocutor de Hamlet, é um idólatra do príncipe e é quem permite a aproximação do público ao personagem título. O velho é,ainda, como o próprio príncipe da Dinamarca, uma vez que Hamlet testa até onde se estende a força de sua consciência antes dos limites da morte. Ambos, ao seu modo, resistem pegando em armas contra o mar e, assim, em suas extremas sensibilidades, se configuram como liberdades solitárias, conscientes das possibilidades ilimitadas de suas consciências, mas em luta consigo mesmas. São personagens em intenso conflito interno provocado por uma realidade opressiva e levados a uma radicalidade da introspecção, que pode culminar em luz ou trevas. Seus interiores estão em gradativa expansão, em um processo pleno de contraditoriedades e de acentuamento das solidões.

Percebe-se, ainda, que no V Ato da tragédia o príncipe representa uma apoteose da própria morte e, do ferimento fatal até "o resto é silêncio", há uma grande extensão.Da mesma maneira, os infartos e devaneios do velho são uma extensão, uma dilatação e um adiamento da própria morte. Talvez, "Discurso do coração infartado" seja todo ele um movimento de precipitação agonizante e delirante da morte. Ao mesmo tempo, se luta contra ela. Já que na tragédia de Shakespeare as ações se desenvolvem como uma reação de Hamlet ao fantasma, as ações do velho são também reações aos seus fantasmas interiores, como a frustração e o desejo,

EM TESE

BELO HORIZONTE

v. 19

N. 1

JAN.ABR. 2013

VERTCHENKO. Discurso do coração infartado [resenha]

P. 348-354 
3. SHAKESPEARE, William. Hamlet. In: BLOOM, Harold. Hamlet: poema ilimitado. Tradução de Jose Roberto O Shea. Inclui texto integral de "Hamlet", traduzido por Anna Amélia de Queiroz Carneiro de Mendonça. Rio de Janeiro: Objetiva, 2004. pp. 301.

4. KOSELLECK, Reinhart. Futuro Passado: Contribuição à semântica dos tempos historicos. Rio de Janeiro: e exteriores, como as atormentações da vizinha. São ações que permitem que seu coração continue em luta, palpitando. Desse modo, o velho Horácio é corporificação, não dita em palavras, do trecho de "Hamlet": "Dentro do peito eu tinha algo lutando/ Que me impedia de dormir." ${ }^{3}$ No espetáculo em questão, esses versos não ditos se tornam ainda mais carregados de significados múltiplos e camadas poéticas, já que o infarto é uma luta dentro do peito, que lhe provoca insônia, mas há, também, uma luta pela plenitude do ser na realização dos desejos que não o abandona naquela noite.

No outro ponto de interseção, por meio do qual o espetáculo estabelece amplo diálogo, encontra-se a obra de Samuel Beckett. Estão presentes a solidão, a incomunicabilidade (reforçada pelo fato de Horácio ser estrangeiro e não entendermos certas palavras), o vazio, a ausência de sentido para a existência humana, a relativização do tempo, a crítica ao projeto de homem moderno. Situar a obra de Beckett e o chamado "Teatro do Absurdo" é percebê-los como resposta filosófica e estética a um ser e estar incerto no mundo, provocados por uma crise da tradição intelectual moderna Se pensarmos a temporalidade enquanto articulação social e atitude perante o mundo, retomando o historiador alemão Reinhart Kosellecck, ${ }^{4}$ se faz possível a observação de períodos históricos pelo reconhecimento da forma que seu homem se relaciona com o tempo, tendo-se em conta que o presente se faz por uma articulação entre o campo de experiências e o horizonte de expectativas. A modernidade cria uma ideia de tempo progressivo e em linha reta, e, por meio dos eventos puramente humanos, nega-se o passado pelas práticas do presente. Este é um espaço insatisfatório, de transitoriedade, para que, por meio da crítica racional se abra um campo de projeções. As bases da ideia moderna de revolução, de progresso, de transformação histórica, de onipotência humana via razão, estão ancoradas aí, de forma que o fim da história é o aprimoramento do mundo, o progresso, seja ele das mais diversas formas. A partir do século XIX, mas sobretudo no século XX, a percepção do tempo como sucessão progressiva, evolução contínua e unidade, e, mais do que isso, as crenças no projeto de homem moderno sofreram diversas críticas e abalos, como as teorias freudianas, a II Guerra Mundial e as crises nos ideais de esquerda. Dessa maneira, a partir da segunda metade do século XX, o esgotamento de alguns valores iluministas e humanistas (lembrando que a racionalidade fora levada ao limite da barbárie),gerou outra concepção e percepção de tempo. O processo histórico se esvazia de sentido e isso muda a experiência do tempo. O horizonte de expectativas é bloqueado e o presente se faz contínuo.

O teatro de Beckett é, ao mesmo tempo, resultado e constatação do fracasso de sistemas filósoficos e de formas de ver

\begin{tabular}{|c|c|c|c|c|c|}
\hline EM TESE & BELO HC & v. 19 & N. 1 & JAN.-ABR. 2013 & VERTCHENKO. Discurso do coração infartado [resenha] \\
\hline
\end{tabular}


o mundo -desejosas de conhecer e explicar racionalmente o universo e o homem e de criar representações mentais da realidade. A trajetória moderna, de perpétua busca pela inteligibilidade, deságua em ausência de sentido como padrão para o conhecimento e também como valor. O universo da experiência humana é o espetáculo do fracasso, do tempo estanque, da inintegibilidade, da falência da racionalidade. A literatura do absurdo expressa o estado mental provocada por essas constatações, por essa perda de referências,por um "desencantamento" (destavez secular) do mundo. Constituiu-se, assim, poderoso instrumento crítico da tradição filosófica ocidental e do homem moderno e de seus projetos calcados na razão e no progresso.

A profunda angústia existencial marcante na obra do escritor irlandês ressoa nas bases de "Discurso do coração infartado". Horácio não tem para onde ir, e todos os dias são iguais em sua rotina solitária. $\mathrm{O}$ apartamento o enterra tal qual Winnie, de "Dias Felizes”, está enterrada em seu buraco. Ambos encontram na potência da linguagem uma forma de resistência para a morte, oscilando entre a consciência do fim e a vontade de ignorá-lo. No entanto, é no absurdo da espera, em meio a jogos silenciosos, que o velho torna-se capaz de encontrar um sentido para sua existência, e este sentido reside em "Hamlet". O que se quer dizer é que só a ausência de finaldidade na vida de Horácio pode permitir finalmente, o seu devaneio shakesperiano.Ou seja, por não suportar a ausência de sentido, Horácio busca "Hamlet", criando e imaginando sentidos, que nada mais são do que padrões de impelimento ilusórios, mas nem por isso pouco legítimos. Nessa fantasia, ele confronta a sua existência e experiencia a ação do tempo. Pode-se suspeitar, então, que o espetáculo é acirramento da esperança pós-Becket, uma vez que o coração de Horácio palpita e preenche a sua espera, encontrando um sentido, ainda que sua vida caminhe para a morte. E isso pode revelar um retorno (para o bem ou para o mal) a esperanças humanistas, como se Beckett abrisse espaço para a reinvenção do humano por meio de Shakespeare.

O que se tem em "Discurso do coração infartado" é a exploração de possibilidades de sentido para a vida humana. O coração incerto do velho Horácio, em sua interminável espera, nos faz ver linhas de força onde o trágico e o cômico se confundem, revelando um universo absurdo ao mesmo tempo estranho e próximo às nossas vidas. Ao dialogar com Shakespeare e Beckett, o espetáculo tensiona e mescla, indefinidamente, percepções temporais distintas, situando a luz ora antes, ora no fim do túnel. O próprio título coloca a obra em zona de instabilidade lírica, já que se trata de um discurso (categoria racional) de um "coração" que sai de seu funcionamento esperado, de sua normalidade, em ritmos diversos 
e apreensões, em cujas tensões acirra-se a poesia. "Discurso do coração infartado" é invenção poética.

\section{REFERÊNCIAS}

BLOOM, Harold. Hamlet: poema ilimitado. Tradução de José

Roberto O 'Shea. Inclui texto integral de "Hamlet", traduzido por Anna Amélia de Queiroz Carneiro de Mendonça. Rio de Janeiro: Objetiva, 2004. pp. 301

BLOOM, Harold. Shakespeare: a invenção do humano. Tradução de José Roberto O`Shea. Rio de Janeiro: Objetiva, 2001.

ESSLIN, Martin. 0 teatro do absurdo. Tradução de Bárbara Heliodora. Rio de Janeiro: Zahar Editores, 1968.

KOSELLECK, Reinhart. Futuro Passado: Contribuição à semântica dos tempos históricos. Rio de Janeiro: Contraponto-Ed. PUC-Rio, 2006

SHAKESPEARE, William. Hamlet. In: BLOOM, Harold. Hamlet: poema ilimitado. Tradução de José Roberto O 'Shea. Inclui texto integral de "Hamlet", traduzido por Anna Amélia de Queiroz Carneiro de Mendonça. Rio de Janeiro: Objetiva, 2004. pp. 301.

WEBB, Eugene. As peças de Samuel Beckett. Tradução de Pedro Sette-Câmara. São Paulo: É Realizações Editora, 2012. 